\title{
Making a Pitch
}

\author{
DIANE ZABEL
}

The Pennsylvania State University, University Park

dxz2@psu.edu

Perhaps I have baseball on my mind as the Los Angeles Dodgers are celebrating their first World Series win since 1988 as I am writing this introduction. While this is not a thematic issue, it struck me that each article in this regular issue of Ticker features tenacious librarians who are making a series of successful pitches for resources, services, or spaces. Each member of the Academic Business Library Directors (ABLD) group must submit an annual report on new and ongoing initiatives, collections, organizational changes, business school changes, library spaces, and other factors impacting their library. Greg Fleming and Emily Miles have carefully read through these reports and have summarized trends in their paper "When Classic Meets Modern." Since these reports were submitted during the beginning months of COVID-19, the impact of the pandemic was still uncertain. However, there is reason for optimism after reading this engaging summary since there are many examples of innovative approaches to providing remote access to services and collections.

While COVID-19 may have put library renovations on hold, the "Libraries By Design" section brings us two wonderful examples of how tenacity can pay off. Michael Enyart had a vision for his library, one that resulted in the new Business Learning Commons at the University of Wisconsin. He successfully made the pitch for a major remodel by engaging stakeholders. The other case study in this section is an example of perseverance. Bob Hebert finally got a new Business Information Commons at Wake Forest University after tirelessly advocating for it for many years.

Sally Armstrong's article in the "Teaching and Learning" section provides an interesting case study on how to instruct students on making the business pitch. Librarians will welcome her advice on how to engage students. The "Tips" section features an article by Lauren Reiter on how business librarians can make the pitch for promoting financial literacy on their campus. Lauren shows that there are multiple approaches to take. Finally, Kim Buschert, Aleha McCauley, Nick Rochlin, Laura Thorne, and Irena Trebic have contributed a feature article on how librarians at the University of British Columbia have studied the research habits and information needs of entrepreneurs in British Columbia in order to make the case for tailored services. I hope that this issue of Ticker inspires readers to make the pitch for their library, or to aim to transform those library resources and services. 